\title{
Bioethanol production from mixed culture microalgae biomass with temperature hydrolysis variation
}

\author{
I Gede Aditya Juliarnita $^{1}$, Rositayanti Hadisoebroto ${ }^{1 *}$, and Astri Rinanti ${ }^{1}$ \\ ${ }^{1}$ Universitas Trisakti, Environmental Engineering Department, Faculty of Landscape Architecture and Environmental Technology, \\ Jakarta, Indonesia.
}

\begin{abstract}
This preliminary study aims to exploit the biomass of microalgae Chlorella vulgaris; Scenedesmus obliquus; and Chlorococcum sp. in the form of a mixed culture as raw material of alternative fuels. Microalgae were cultivated in the artificial growth medium of PHM (Provasoli Haematococcus Media) for 9 days to reach the exponential phase. Hydrolysis was carried out at a temperature variation of $\left({ }^{\circ} \mathrm{C}\right) 25 ; 80 ; 100 ; 120 ; 140 ; 160$ within 30 minutes by adding hydrochloric acid. Biomass fermentation by adding 50\% (v/v) Saccharomyces cerevisiae for 5 day to produce alcohol compounds. The last stage is separation of the alcohol compounds from another compounds by distillation. The result showed that carbohydrate levels with color change indicator in luff schoorl solution at hydrolysis and fermentation stages severely were $12.20 \mathrm{mg} / \mathrm{L}$. Carbohydrate levels in fermentation stage produced $17 \%(\mathrm{v} / \mathrm{v})$ alcohol compounds while in the distillation stage, $98 \%(\mathrm{v} / \mathrm{v})$ alcohol will be separated into intermediate compounds such as linoleic acid and methyl alcohol as a characteristic of bioethanol. At $80^{\circ} \mathrm{C}$ of hydrolysis temperature, $58 \%$ bioethanol was produced. Further research is needed, since the preliminary study proves the mixed culture of microalgae is potentially to be utilized in producing bioethanol.
\end{abstract}

\section{Introduction}

The demand of energy increasing and trigger us to seek alternative energy. Alternative energy demand has increased by $25 \%$ by 2015 [1-2]. Alternative energy such as bioethanol is easy to find and renewable from organic matter. Bioethanol is a fermentation product of organic material that can be made from carbohydrate-containing substrates (sugar, starch, and cellulose) with chemical formula $\mathrm{C} 2 \mathrm{H} 5 \mathrm{OH}$ in the form of colorless, volatile liquid, with a specific odor [3]. One source of renewable carbohydrates and an abundance in environments is the microalgae.

Microalgae are microcospic-sized unicellular living creatures that live in fresh or marine water, which have chlorophyll, so they can fix carbon dioxide, through the photosynthesis process [2]. Microalgae produce primary metabolites in the form of proteins, carbohydrates, fats, and nucleic acids. Research on microalgae as an alternative energy source has been widely conducted, but more focused on biodiesel and biogas production than bioethanol. Whereas theoretically microalgae can produce bioethanol naturally by optimizing its intracellular potential [4].

Environmental conditions optimization is indispensable in growing microalgae in batch culture to obtain high carbohydrate production. Suitable culture temperature, acidity degree between 6-7, and lighting between 2000 lux to 4000 lux, are such environmental conditions must be maintained to obtain high metabolic yields of microalgae [5-6].

In bioethanol production, there are 4 stages to be done, namely cultivation of microalgae, hydrolysis, fermentation and distillation. The hydrolysis process is highly dependent on temperature. The right temperature allows to breakdown of carbohydrates contained in the cell wall perfectly [7-8]. Therefore, this study aims to obtain the appropriate temperature for the ongoing hydrolysis process, as an effort to increase the production of bioethanol.

\section{Research methodology}

\subsection{Cultivation}

This study used 3 types of green microalgae namely Chlorella vulgaris, Scenedesmus obliquus, and Chlorococcum Sp. in the form of contructed consortium cultivated in PHM (Provasoli Haematococcus Media). The cultivation operational conditions as bacth cultures in the 3-liter photobioreactor are arranged as follows: acidity level at 6 , temperature of $27^{\circ} \mathrm{C}$, light intensity of 4000 lux for 24 hours, and aerated in 0.3 liters $/ \mathrm{sec}$. Biomass is harvested from sediment through centrifugation $3000 \mathrm{rpm}$ for 15 minutes.

\footnotetext{
* Corresponding author: rositayanti@trisakti.ac.id
} 


\subsection{Hydrolysis}

The resulting biomass is hydrolysed using a strong acid of $\mathrm{HCl}$ (hydrochloric acid). Hydrolysis was carried out by adding $25 \mathrm{ml}$ of hydrochloric acid into 1 gram of dry biomass under conditions of temperature variation $\left({ }^{\circ} \mathrm{C}\right)$ $80,100,120,140$, and 160 for 30 minute and room temperature as control.

\subsection{Fermentation}

The hydrolyzed biomass is fermented with Saccharomyces cerevisiae yeast at $25^{\circ} \mathrm{C}$ for 5 days. Further fluid formed will be moistened by using the distillation method.

\subsection{Distillation}

Distillation is carried out to separate between water and alcohol which is a product derived from the fermentation stage. The resulting destylate will then be tested by GCMS to determine the characteristics of the ethanol compound.

\section{Result and discussion}

\subsection{Cultivation of microalgae cosortium}

The cultivated microalgae consortium in 3-liter photobioreactor is harvested by means of precipitation and then the sediment is centrifuged to separate the biomass with the remaining water. The harvesting time is carried out in the exponential phase that occurs on the 9th day.

In day 9th, the formation of biomass reach its highest rate due to the rapid nutrient absorption activity, which can increase the production of metabolite. If the harvesting of the microalgae is carried out at the stationary phase or more than 9 days, then the cell growth rate is balanced with the cell death rate. This can reduce the formation of metabolites [9].

\subsection{The effect of hydrolysis temperature}

The resulting dry biomass is then processed at the hydrolysis stage. Carbohydrate levels at each temperature variation are shown in Table 1.

Table 1. The effect of hydrolysis temperature on carbohydrate level.

\begin{tabular}{|c|c|c|c|c|c|}
\hline \multirow{3}{*}{ Temperature $\left({ }^{\circ} \mathrm{C}\right)$} & \multirow{3}{*}{ Biomass (mg) } & \multicolumn{4}{|c|}{ Carbohydrate Levels (mg/L) } \\
\hline & & \multicolumn{2}{|c|}{$\mathrm{C}_{0}$} & \multicolumn{2}{|c|}{$\mathbf{C x}$} \\
\hline & & $\mathbf{R 1}$ & $\mathbf{R 2}$ & $\mathbf{R 1}$ & $\mathbf{R 2}$ \\
\hline 25 (room temp.) & \multirow{6}{*}{$305 \pm 310$} & 3.70 & 4.80 & 4.80 & 6.10 \\
\hline 80 & & 10.48 & 10.22 & 12.20 & 12.20 \\
\hline 100 & & 9.70 & 9.96 & 11.78 & 11.00 \\
\hline 120 & & 9.54 & 9.96 & 11.78 & 12.04 \\
\hline 140 & & 10.22 & 10.22 & 12.20 & 10.48 \\
\hline 160 & & 9.96 & 9.70 & 11.78 & 12.20 \\
\hline
\end{tabular}

$* \mathrm{Co}=$ Concentration on $\mathrm{t}=0$ minute, $\mathrm{Cx}=$ Concentration on $\mathrm{t}=30$ minute

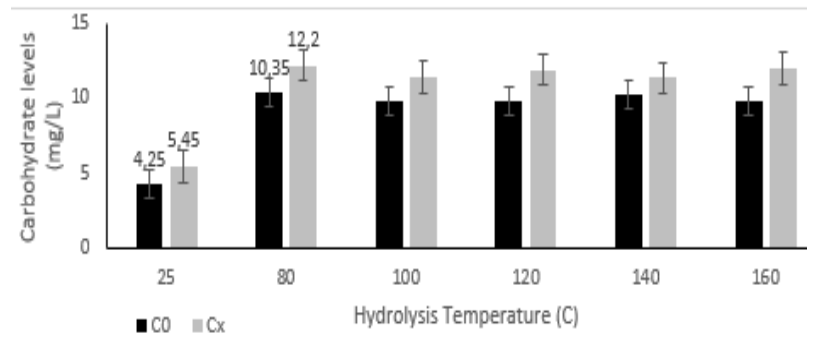

Fig. 1. The Effect of Hydrolysis Temperature on Carbohydrate Level.

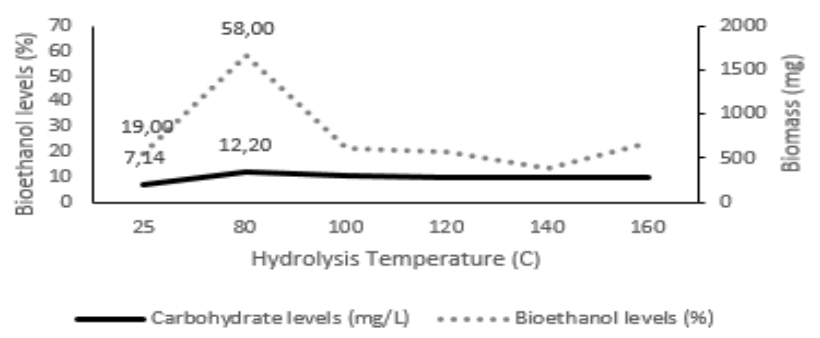

Fig. 2. Effect of hydrolysis temperature by production of bioethanol content.
Hydrolysis of dry biomass is done to break down complex carbohydrates produced from the metabolism of microalgae into simpler carbohydrates [10]. Based on these data, the highest carbohydrate levels were found at $80^{\circ} \mathrm{C}$ hydrolysis temperature. At these temperatures the content in the cell walls of cellulose, pectin, glycoprotein, and mannan which are complex carbohydrate compounds have been degraded [11-12]. This is in accordance with the statement of [12] that the content in the microalgae cell wall which is a complex carbohydrate compound that is easily degraded. In the green microalgae, the main constituent component of cellulose is galactomannan. Galactomannan consists of galactose, glucose, and mannose which is a hexose group having six carbon atoms in each monomer [11].

Galactomannan compounds are then to be fermented to be converted into bioethanol. As seen in Table 1, the determination of hydrolysis temperature greatly affect the carbohydrate levels obtained. Theoretically, the higher the hydrolysis temperature, the greater the carbohydrate levels obtained. The hydrolysis process is also influenced by the quantity of biomass particles to be 
degraded [10]. As the research result show in Table 1, there is no significant increase in carbohydrate levels due to differences in the particle size of the biomass that affects carbohydrate levels so that the hydrolysis process does not occur completely. However, the hydrolysis process can also take place at room temperature but decomposition of carbohydrate biomass does not occur perfectly.

\subsection{Bioethanol production}

High carbohydrate levels will affect the production of ethanol in the fermentation process. Biomass that has been hydrolyzed in fermentation for 5 days are shown at Fig 2.

In Fig. 2, the higher the carbohydrate content, the greater the amount of bioethanol produced. This is confirmed by previous research that the higher levels of carbohydrates present in microalgae biomass the faster the process of changing from carbohydrates to bioethanol, which then increased bioethanol production by $25 \%(\mathrm{v} / \mathrm{v})$ [13]. The process of hydrolysis using room temperature can also produce bioethanol content, but the

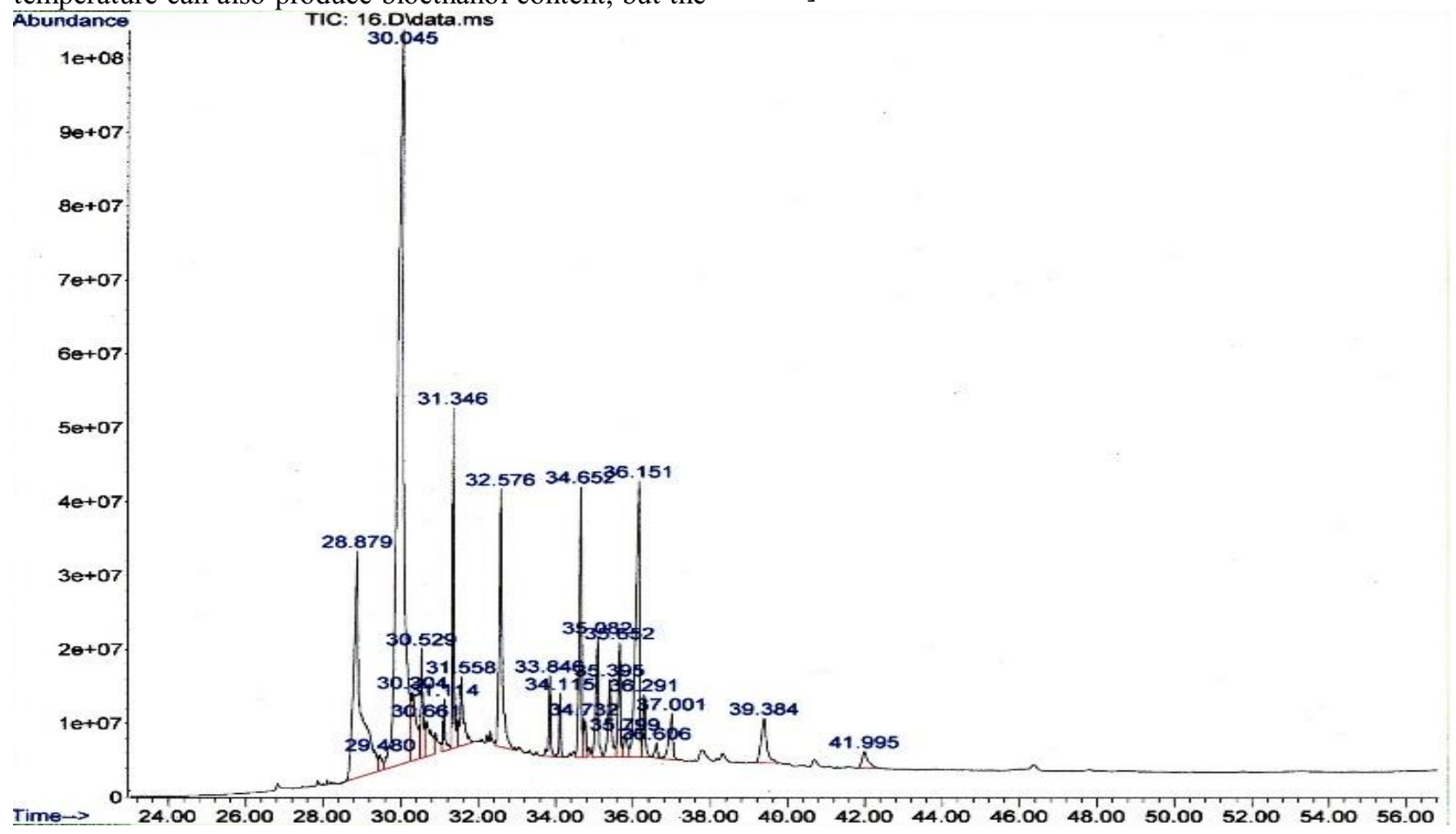

Fig. 3. GC-MS analysis results.

\section{Conclusion}

Carbohydrate levels obtained from the results of microalgae metabolism greatly determine the amount of bioethanol that can be produced. Hydrolysis temperature suitable for decomposing carbohydrate compounds occurs at $80^{\circ} \mathrm{C}$. At that temperature produced the highest carbohydrate level of $12.20 \mathrm{mg} / \mathrm{L}$ and bioethanol production of $58.00 \%(\mathrm{v} / \mathrm{v})$. There is influence of particle sized that can affect carbohydrate levels. formation of bioethanol does not occur perfectly. As seen in Fig. 2, there are several factors that need to be considered such as $\mathrm{pH}$ and temperature to support the fermentation process.

The process of purifying bioethanol by using the distillation method also greatly determines the level of bioethanol to be produced. If the distillation temperature is too high then the water mixed in the fermentation product will also vaporize and then reduce the concentration of the bioethanol. Hydrolysis at $80^{\circ} \mathrm{C}$ yields the highest bioethanol level of $58.00 \%(\mathrm{v} / \mathrm{v})$. The bioethanol product is then analyzed using GC-MS to determine the ethanol characteristics contained in the bioethanol.

In Fig. 3, GC-MS results show that there are highest peak and some other peaks. This result indicate that the bioethanol produced is not $100 \%$ pure, that in the $58.00 \%(\mathrm{v} / \mathrm{v})$ there are $37.25 \%(\mathrm{v} / \mathrm{v})$ linoleic acid which is an acid compound contained in biofuels. The longer fermentation time of Saccharomyces cerevisiae could decompose carbohydrates into other compounds that could interfere the purity of bioethanol production [13$14]$.

\section{References}

1. Matthew D. Leonarda, Efstathios E. Michaelidesa, Dimitrios N. Michaelidesb. Substitution of coal power plants with renewable energy sources - Shift of the power demand and energy storage. Dept. of Engineering, TCU, Fort Worth, TX 76132, USA (2018)

2. Tian-YuanZhang a,b, Hong-YingHu a,b,n, YinHuWu a, Lin-LanZhuang a, Xue-QiaoXu a, XiaoXiong Wang a, Guo-HuaDao. Promising solutions 
to solve the bottlenecks in the large-scale cultivation of microalgae for biomass/bioenergy production. Environmental Simulation and Pollution Control State Key Joint Laboratory, School of Environment, Tsinghua University, Beijing 100084, PRChina (2016)

3. Nahak, sabitri . A Solution To Global Warming Problem. Appl. Microbiol. Biotechnol 1. 1 4: 74-80 (2011)

4. Aitken, Douglas. An Assessment of the Sustainability of Bioenergy Production from Algal Feedstock. Thesis of The University of Edinburgh, South Bridge, United Kingdom (2014)

5. Yi-di Chen, Shih-Hsin Ho, Dillirani Nagarajan, Nan-qi Ren and Jo-Shu Chang. Waste biorefineries — integrating anaerobic digestion and microalgae cultivation for bioenergy production. State Key Laboratory of Urban Water Resource and Environment, School of Municipal and Environmental Engineering, Harbin Institute of Technology, Harbin 150090, PR China (2018)

6. Astri Rinanti, Edwan Kardena, Dea Indriani Astuti, Kania Dewi. Growth Response And Chlorophyll Content Of Scenedesmus Obliquus Cultivated In Different Artificial Media. Faculty of Civil and Environmental Engineering, Bandung Institute of Technology, Indonesia (2013)

7. Rindit, Pambaylun. Laporan Penelitian : Mempelajari Hidrolisis Pati Gadung (Dioscoreahispida Dernst) dengan Enzim $\alpha$-amilase dan Gluko amilase untuk Pembuatan Sirup Glukosa. Fakultas Pertanian UNSRI. Palembang (1998)

8. Taherzadeh MJ, Karimi K. Acid-based hydrolysis processes for ethanol from lignocellulosic materials: a review. Bioresources 2007 ;2:472-99 (2007)

9. M. Isabel Or6s, Eduardo Marco \& Flor Mart/nez.. Suitability of Chlorella vulgaris UAM 101 for Heterotrophic Biomass Production. Departamento de Biologfa (C-XI), Facultad de Ciencias, Universidad Aut6noma de Madrid, 28049 Madrid, Spain (1991)

10. Adrie Veeken, Bert Hamelers. Efect of temperature on hydrolysis rates of selected biowaste Components. Department of Agricultural, Environmental and Systems Technology, Wageningen Agricultural University, P.O. Box 8129, 6700 EV Wageningen, The Netherlands (1998)

11. Harun, R., M.K. Danquah, and G.M. Forde, Microalgal biomass as a fermentation feedstock for bioethanol production. Journal of Chemical Technology and Biotechnology. 85(2): p. 199-203 (2010)

12. Miranda JR, Passarinho PC, Gouveia L. Bioethanol production from Scenedesmus obliquus sugars: the influence of photobioreactors and culture conditions on biomass production. Bioenergy and Biofuels 96, 555-564 (2012)
13. Carlos Eduardo de Farias Silva, Davide Meneghello and Alberto Bertucco. A systematic study regarding hydrolysis and ethanol fermentation from microalgal biomass, Biocatalysis and Agricultural Biotechnology (2018)

14. Silva, C.E.F., Bertucco, A. Dilute acid hydrolysis of microalgal biomass for bioethanol production: an accurate kinetic model of biomass solubilization, sugars hydrolysis and nitrogen/ash balance. Reaction Kinetics, Mechanisms and Catalysis, in Press (2017) 